\title{
Análise financeira da extração e beneficiamento de resíduos florestais pós- colheita na floresta nacional do tapajós
}

\author{
Renato Bezerra da Silva Ribeiro ${ }^{*}$ João Ricardo Vasconcellos Gama ${ }^{1}$ Agostinho Lopes de Souza ${ }^{2}$ Dárlison
} Fernandes Carvalho de Andrade ${ }^{3}$

${ }^{1}$ Universidade Federal do Oeste do Pará, Rua Vera Paz, s/n, Salé, Santarém-PA, 68040-255

${ }^{2}$ Universidade Federal de Viçosa, Avenida Peter Henry Rolfs, s/n - Campus Universitário, Viçosa-MG, 36570-900

${ }^{3}$ Instituto Chico Mendes de Conservação da Biodiversidade, Complexo Administrativo, Setor Sudoeste, Brasilia-DF, 70.670-350

*Author for correspondence: renato.ribeiro@ufopa.edu.br

Received: September 2017 / Accepted: May 2019 / Published: June 2019

\begin{abstract}
Resumo
O objetivo do estudo foi identificar e analisar os custos e as receitas estimadas na extração e beneficiamento de resíduos florestais pós-colheita na Flona Tapajós. Os dados foram da Área de Manejo Florestal da COOMFLONA, Unidade de Produção Anual 7 (UPA 7). Foram extraídos e beneficiados os resíduos de 11 espécies comerciais com uso em movelaria e na construção civil. As etapas envolvidas foram: localização e preparação, operação de arraste, operações de pátio, beneficiamento e transporte/armazenamento da madeira serrada. Os dados dos custos reais e estimados com a previsão de encargos sociais e trabalhistas e as receitas estimadas, considerando os preços de madeira serrada no mercado formal e no mercado informal praticados na cidade de Santarém, assim como o preço de venda na forma de dormentes, foram avaliados em 8 cenários de rentabilidade. Foi extraído $260,7036 \mathrm{~m}^{3}$ de resíduos e deste, $157,6402 \mathrm{~m}^{3}$ foram beneficiados, gerando $84,1005 \mathrm{~m}^{3}$ de madeira serrada (53\% de rendimento). Cinco cenários avaliados tiveram lucro, sendo que as melhores opções indicaram uso múltiplo com dormentes e madeira serrada para produção em movelaria. O cenário que envolveu todos os direitos trabalhistas aos manejadores foi o que apresentou melhor forma de remuneração e a receita estimada agregou valor a madeira beneficiada dos resíduos.
\end{abstract}

Palavras-chave: Madeira serrada, Agregação de valor, Manejo florestal comunitário

\footnotetext{
Abstract

The objective of the study was to identify and analyze the estimated costs and revenues in the extraction and processing of post-harvest forest residues at Flona Tapajós. The data were from the Forest Management Area of COOMFLONA, Annual Production Unit 7. The forest residues from 11 commercial species was extracted and benefited to furniture and construction. The steps involved were: localization and preparation, drag operation, patio operations, processing and transportation / storage of the lumber. The data of the actual and estimated costs to the forecast of social and labor charges and the estimated revenue, considering wood prices sawed in the formal sector and the informal market practiced in the city of Santarém, as well as the sale price in the form of dormant, were evaluated in 8 profitability scenarios. It was extracted $260.7036 \mathrm{~m}^{3}$ of waste and this, $157.6402 \mathrm{~m}^{3}$ benefited generating $84.1005 \mathrm{~m}^{3}$ of lumber (53\% yield). Five scenarios evaluated had a profit, and the best options indicated multiple use with sleepers and lumber for furniture production. The scenario that involved all labor rights to managers showed the best form of compensation
}

and the estimated revenue value added wood benefited forest residues.

Keywords: Sawn wood, Adding value, Community Forest Management

\section{Introdução}

As discussões envolvendo o aproveitamento econômico de resíduos florestais da colheita madeireira já vêm sendo tratada como uma possibilidade de melhor utilização da madeira. Todavia, a principal indicação para estes resíduos tem sido a geração de energia, por meio do carvão vegetal e lenha (Jankauskis 1983; Graça e Campos 1986; Numazawa 1986; Souza 2009).

Simonhane (2013) comenta que a produção de energia (lenha e carvão) com resíduos de diâmetros acima de 20 $\mathrm{cm}$ é a forma menos nobre de aproveitar este recurso, mas que por vezes as empresas veem como a melhor forma de aproveitamento desse material lenhoso.

Os resíduos florestais das árvores derrubadas no manejo florestal são divididos, de forma simples, em galhos grossos e finos, folhas e raízes (Salmeron 1980). Sendo que os galhos são a parte mais indicadas para aproveitamento, devido à quantidade dessa matéria-prima e por apresentar maior facilidade de quantificação quando comparada as outras.

Tratando-se de uma floresta natural de terra firme, os resíduos florestais oriundos das árvores colhidas são uma alternativa atrativa de aproveitamento, haja vista, a possibilidade de agregar maior valor econômico às espécies. Todavia, torna-se necessário a melhor utilização deste recurso florestal levando em consideração o uso múltiplo dos resíduos (Souza 2009).

As árvores de grande porte geram resíduos de galhos grossos com diâmetros que possibilitam o beneficiamento e a utilização da madeira serrada para o setor moveleiro e de fabricação de pequenos artefatos, além do setor de précortados. No entanto, não há experiências, publicadas, voltadas para esses aproveitamentos com os resíduos de espécies nativas da Amazônia e muito menos análises sobre a viabilidade econômica de tal atividade.

A análise financeira é usada por empreendimentos para gerar critérios de decisões, avaliando a rentabilidade de uma atividade florestal permitindo prever antecipadamente a possibilidade de ganho ou perdas. E quando essa é feita após a realização da atividade, é possível determinar quais foram as atividades que causaram lucros ou prejuízos e qual foi o rendimento financeiro (Pokorny et al. 2011).

$\mathrm{Na}$ Área de Manejo Florestal (AMF) da Cooperativa Mista da Floresta Nacional do Tapajós (COOMFLONA), os resíduos estão sendo beneficiados e destinados para o setor moveleiro da região oeste do Pará e atendem a um 
mercado local de pré-cortados, com peças em bitolas de pequenas dimensões. Esta iniciativa pioneira na região visa a priori expandir a produção para abastecer os pólos moveleiros na cidade de Belterra, Mojuí dos Campos e Santarém, além de manter a fabricação de móveis e précortados por comunitários em movelarias localizadas na Floresta Nacional do Tapajós.

Desta forma, o objetivo deste estudo foi analisar a viabilidade econômica do aproveitamento de resíduos da colheita florestal na Floresta Nacional do Tapajós.

\section{Material e métodos}

Área de estudo

O estudo foi realizado na Área de Manejo Florestal da Cooperativa Mista da Flona Tapajós (COOMFLONA), especificamente na Unidade de Produção Anual número sete (UPA 7). Esta área fica localizada na Floresta Nacional do Tapajós, km 83 da BR 163, munícipio de Belterra.

O clima da região pela classificação de Köppen é do tipo Ami, com temperatura média anual de $25,5^{\circ} \mathrm{C}$ e umidade relativa média em torno de $90 \%$. A precipitação média anual é de $1820 \mathrm{~mm}$, com grande incidência de chuvas no período de janeiro a maio (Ibama 2004). Segundo dados do Radam Brasil (1976), a área de estudo se encontra na unidade morfoestrutural Planalto TapajósXingú, cuja cota altimétrica varia entre 120 e 170 metros.

Os solos predominantes na Unidade são os Latossolos Amarelo Distrófico, solos profundos e com baixa capacidade de troca catiônica (Radambrasil 1976). A Floresta Nacional do Tapajós situa-se na zona de Floresta Ombrófila Densa, tipo de vegetação dominante no norte do país (IBGE, 2012), caracterizado pelo domínio de árvores de grande porte, sob regime de temperaturas elevadas e precipitações distribuídas ao longo do ano (Ibama 2004).

\section{Coleta e análise dos dados}

Os resíduos florestais das árvores colhidas, com diâmetros aproveitáveis para madeira serrada $(\mathrm{d} \geq 20 \mathrm{~cm}$ e comprimento $\geq 50 \mathrm{~cm}$ ), foram extraídos e beneficiados na UPA 7. As espécies comerciais que fizeram parte deste estudo estão apresentadas na Tabela 1, com suas respectivas densidades básicas.

Tabela 1. Espécies comerciais utilizadas no estudo com respectivas densidades básicas

\begin{tabular}{clc}
\hline$\#$ & \multicolumn{1}{c}{ Espécie } & $\begin{array}{c}\text { Densidade básica } \\
\left(\mathbf{k g} / \mathbf{m}^{3}\right)^{*}\end{array}$ \\
\hline 1 & $\begin{array}{l}\text { Hymenolobium heterocarpum Ducke } \\
\text { (Angelim-pedra) }\end{array}$ & 590 \\
2 & $\begin{array}{l}\text { Vochysia assua Stafleu (Cedrorana) } \\
3\end{array}$ & $\begin{array}{l}\text { Pseudopiptadenia suaveolens (Miq.) } \\
\text { J.W.Grimes (Fava-timborana) }\end{array}$ \\
4 & $\begin{array}{l}\text { Apuleia leiocarpa (Vogel) J.F.Macbr. } \\
\text { (Garapeira) }\end{array}$ & 760 \\
5 & $\begin{array}{l}\text { Mezilaurus itauba } \text { Taubert ex Mez. (Itaúba) } \\
6\end{array}$ & 670 \\
7 & $\begin{array}{l}\text { Aniba burchellii Kosterm. (Louro-rosa) } \\
\text { (Maçaranduba) }\end{array}$ & 800 \\
8 & $\begin{array}{l}\text { Astronium lecointei } \text { Ducke (Muiracatiara) } \\
9\end{array}$ & 642 \\
1 & Erisma uncinatum Warm. (Quaruba) & 810 \\
1 & $\begin{array}{l}\text { Lecythis pisonis } \text { Cambess. (Sapucaia) } \\
1\end{array}$ & $\begin{array}{l}\text { Diplotropis purpurea } \text { (Rich.) Amshoff } \\
\text { (Sucupira-amarela) }\end{array}$ \\
\hline *Fonte: Instituto de Pesquisas Tecnológica - IPT & 890 \\
\hline
\end{tabular}

As etapas envolvidas no levantamento foram: localização e preparação, operação de arraste, operações de pátio, beneficiamento e transporte/armazenamento da madeira serrada. Os resíduos foram beneficiados nos pátios de estocagem por uma serraria portátil para a geração de madeira serrada.

Os dados de todos os custos envolvidos foram registrados em fichas de campo específicas, sendo que estes corresponderam aos materiais, equipamentos, mãode-obra e combustível utilizados em todo o levantamento. Em contrapartida, a receita foi estimada baseando-se nos preços da madeira serrada das espécies estudadas, no mercado formal e informal obtidas na cidade de Santarém, por esta ainda absorver toda a produção da COOMFLONA (Tabela 2).

Tabela 2. Preços de madeira serrada no mercado formal (PMF) e informal (PMI) de Santarém para as espécies estudadas

\begin{tabular}{|c|c|c|}
\hline Espécie & $\begin{array}{c}\text { PMF } \\
\left(\mathbf{R} \$ \cdot \mathbf{m}^{3}\right)^{-1}\end{array}$ & $\begin{array}{c}\text { PMI } \\
\left(\mathbf{R} \$ . \mathbf{m}^{3}\right)^{-1}\end{array}$ \\
\hline $\begin{array}{l}\text { Hymenolobium heterocarpum (Angelim- } \\
\text { pedra) }\end{array}$ & 650,00 & 600,00 \\
\hline Vochysia assua (Cedrorana) & 700,00 & 650,00 \\
\hline $\begin{array}{l}\text { Pseudopiptadenia suaveolens (Fava- } \\
\text { timborana) }\end{array}$ & 700,00 & 550,00 \\
\hline Apuleia leiocarpa (Garapeira) & 900,00 & 800,00 \\
\hline Mezilaurus itauba (Itaúba) & $1.100,00$ & 800,00 \\
\hline Aniba burchellii (Louro-rosa) & 650,00 & 600,00 \\
\hline Manilkara huberi (Maçaranduba) & 900,00 & 900,00 \\
\hline Astronium lecointei (Muiracatiara) & $1.100,00$ & 800,00 \\
\hline Erisma uncinatum (Quaruba) & 700,00 & 550,00 \\
\hline Lecythis pisonis (Sapucaia) & 900,00 & 650,00 \\
\hline $\begin{array}{l}\text { Diplotropis purpurea (Sucupira- } \\
\text { amarela) }\end{array}$ & 900,00 & 800,00 \\
\hline
\end{tabular}

Além disso, foi estimada a utilização da madeira serrada dos resíduos para uso como dormentes. O dormente é o elemento da superestrutura ferroviária que tem por função receber e transmitir ao lastro os esforços e vibrações produzidos pelas cargas dos trens, servindo de suporte e fixação dos trilhos (Silva e Evangelista 2011).

As dimensões (bitola) dos dormentes variam conforme a via ferroviária e a sua utilização, sendo que a dimensão estimada neste estudo foi de peças de $17 \mathrm{~cm} \mathrm{x}$ $24 \mathrm{~cm} \times 280 \mathrm{~cm}$, também chamada de bitola larga e mais usual nas ferrovias atuais, as quais representam em torno de $80 \%$ da malha ferroviária no Brasil (Silva e Evangelista 2011).

A madeira para ser destinada para dormente tem que apresentar durabilidade, rigidez, elasticidade e resistência a esforços. Portanto, as espécies que possuem estas características e fizeram parte desta estimativa, foram: Hymenolobium heterocarpum, Apuleia leiocarpa, Mezilaurus itauba, Manilkara huberi, Lecythis pisonis e Diplotropis purpurea. Para a estimativa destas espécies levou-se em consideração os dois tipos de uso, sendo madeira serrada para o setor de móveis e dormentes.

Por se tratar de madeira de espécies nativas, o preço de dormente utilizado para estimar a receita foi de $\mathrm{R} \$ 270,00$ a peça, que é $50 \%$ maior que o valor vendido com a madeira de eucalipto tratada na bitola larga $(\mathrm{R} \$ 180,00)$. Esta opção visa maior agregação de valor e promoção do uso múltiplo desta matéria-prima que antes ficava na floresta sem nenhum uso comercial. 
De posse destas informações foram avaliados oito cenários para verificar a rentabilidade econômica deste tipo de atividade (Tabela 3), levando em consideração os custos reais pagos pela cooperativa (mão-de-obra sem encargos sociais) e reavaliando com a inclusão dos benefícios sociais, obtendo assim a remuneração justa pela matéria-prima, conforme orientam a OIT - Organização Internacional do Trabalho e o SBF - Serviço Florestal Brasileiro (2009).

Tabela 3. Cenários avaliados no estudo com resíduos florestais na Floresta Nacional do Tapajós.

\begin{tabular}{cll}
\hline Cenários & \multicolumn{1}{c}{ Custos } & Estimativa de receita \\
\hline 1 & $\begin{array}{l}\text { Sem encargos sociais e } \\
\text { trabalhistas }\end{array}$ & Mercado formal \\
\hline 2 & $\begin{array}{l}\text { Sem encargos sociais e } \\
\text { trabalhistas }\end{array}$ & Mercado informal \\
\hline 3 & $\begin{array}{l}\text { Com previsão de encargos } \\
\text { sociais e trabalhistas }\end{array}$ & Mercado formal \\
\hline 4 & $\begin{array}{l}\text { Com previsão de encargos } \\
\text { sociais e trabalhistas }\end{array}$ & Mercado informal \\
\hline 5 & $\begin{array}{l}\text { Sem encargos sociais e } \\
\text { trabalhistas }\end{array}$ & $\begin{array}{l}\text { Mercado formal }+ \\
\text { dormentes }\end{array}$ \\
\hline 6 & $\begin{array}{l}\text { Sem encargos sociais e } \\
\text { trabalhistas }\end{array}$ & $\begin{array}{l}\text { Mercado informal }+ \\
\text { dormentes }\end{array}$ \\
\hline 7 & $\begin{array}{l}\text { Com previsão de encargos } \\
\text { sociais e trabalhistas }\end{array}$ & $\begin{array}{l}\text { Mercado formal }+ \\
\text { dormentes }\end{array}$ \\
\hline 8 & $\begin{array}{l}\text { Com previsão de encargos } \\
\text { sociais e trabalhistas }\end{array}$ & $\begin{array}{l}\text { Mercado informal }+ \\
\text { dormentes }\end{array}$ \\
\hline
\end{tabular}

O pagamento aos manejadores durante toda atividade foi realizado na forma de diária, sem a inclusão de benefícios sociais e trabalhistas. Desta forma, nos cenários $3,4,7$ e 8 , os custos com mão-de-obra incluíram o pagamento de salário mensal acrescidos dos encargos sociais e trabalhistas conforme apresentado na Tabela 4 .

Tabela 4. Encargos sociais e trabalhistas utilizados para a estimativa do pagamento de mão-de-obra

\begin{tabular}{lc}
\hline \multicolumn{1}{c}{ Encargos Sociais e Trabalhistas } & $\%$ \\
\hline INSS & 20,00 \\
Seguro contra Acidente de Trabalho & 3,00 \\
Salário Educação & 2,50 \\
INCRA/SEST/SEBRAE/SENAT & 3,30 \\
FGTS & 8,00 \\
FGTS/Provisão de Multa para Rescisão & 4,00 \\
Previdenciário s/ 13º e Férias & 7,93 \\
13 ${ }^{\circ}$ Salário & 8,33 \\
Férias & Total de Encargos \\
\hline
\end{tabular}

A porcentagem dos encargos foi baseada em um salário de mensalista de uma empresa não optante pelo simples, haja vista, que a receita bruta da cooperativa com a venda da madeira em tora é, em média, superior a $\mathrm{R} \$ 2,4$ milhões/ano. Além dos encargos sociais e trabalhistas foi acrescido $30 \%$ de adicional de remuneração de periculosidade, devido aos riscos envolvidos na atividade. Todas as margens percentuais tiveram como base o salário mínimo vigente (2013) de $\mathrm{R} \$ 678,00$.

\section{Resultados}

Dados gerais

Foram extraídos 260,7036 $\mathrm{m}^{3}$ de resíduo (galhos grossos), correspondente as 11 espécies comerciais
(Tabela 5). A extração ocorreu em duas Unidades de Trabalho (UTs), num total de 11 pátios de estocagem trabalhados, o que representou $13,7 \%$ do número total de pátios na UPA 7.

Tabela 5. Lista de espécies comerciais com os seus respectivos volumes de resíduos extraídos na Área de Manejo Florestal da COOMFLONA

\begin{tabular}{|c|c|c|}
\hline Espécie & $\mathbf{V}_{\text {resíduo }}\left(\mathbf{m}^{3}\right)$ & $\%$ \\
\hline H. heterocarpum (Angelim-pedra) & 9,8895 & 7,6 \\
\hline V. assua (Cedrorana) & 24,1354 & 9,3 \\
\hline P. suaveolens (Fava-timborana) & 7,2333 & 2,8 \\
\hline A. leiocarpa (Garapeira) & 12,1133 & 4,6 \\
\hline M. itauba (Itaúba) & 5,1121 & 2,0 \\
\hline A. burchellii (Louro-rosa) & 22,0300 & 8,5 \\
\hline M. huberi (Maçaranduba) & 83,6850 & 32,1 \\
\hline A. lecointei (Muiracatiara) & 70,8139 & 27,2 \\
\hline E. uncinatum (Quaruba) & 11,2639 & 4,3 \\
\hline L. pisonis (Sapucaia) & 2,0591 & 0,8 \\
\hline D. purpurea (Sucupira-amarela) & 2,3680 & 0,9 \\
\hline Total & 260,7036 & 100,0 \\
\hline
\end{tabular}

O volume bruto beneficiado foi de $157,6402 \mathrm{~m}^{3}$ e deste foi gerado $84,1005 \mathrm{~m}^{3}$ de madeira serrada, tendo um rendimento médio de 53,3\%, sendo que algumas espécies que apresentaram rendimento superior (Tabela 6).

Tabela 6. Rendimento de madeira serrada pelo beneficiamento dos resíduos florestais na Área de Manejo Florestal da COOMFLONA

\begin{tabular}{|c|c|c|c|}
\hline Espécie & $\begin{array}{c}V_{\text {resíduo }} \\
\left(\mathbf{m}^{3}\right)\end{array}$ & $\begin{array}{c}\mathbf{V}_{\text {serrado }} \\
\left(\mathbf{m}^{3}\right)\end{array}$ & $\begin{array}{l}\text { Rendimento } \\
(\%)\end{array}$ \\
\hline $\begin{array}{l}\text { H. heterocarpum (Angelim- } \\
\text { pedra) }\end{array}$ & 16,5436 & 10,2952 & 62,2 \\
\hline V. assua (Cedrorana) & 15,3696 & 7,2973 & 47,5 \\
\hline $\begin{array}{l}\text { P. suaveolens (Fava- } \\
\text { timborana) }\end{array}$ & 4,9085 & 3,2588 & 66,4 \\
\hline A. leiocarpa (Garapeira) & 3,3704 & 1,9873 & 59,0 \\
\hline M. itauba (Itaúba) & 4,5114 & 2,4486 & 54,3 \\
\hline A. burchellii (Louro-rosa) & 14,6387 & 7,4850 & 51,1 \\
\hline M. huberi (Maçaranduba) & 41,3064 & 21,0056 & 50,9 \\
\hline A. lecointei (Muiracatiara) & 43,7267 & 24,2687 & 55,5 \\
\hline E. uncinatum (Quaruba) & 9,0686 & 4,0710 & 44,9 \\
\hline L. pisonis (Sapucaia) & 1,8284 & 0,5060 & 27,7 \\
\hline $\begin{array}{l}\text { D. purpurea (Sucupira- } \\
\text { amarela) }\end{array}$ & 2,3680 & 1,4769 & 62,4 \\
\hline Total & 157,6402 & 84,1005 & 53,3 \\
\hline
\end{tabular}

As espécies $H$. heterocarpum, $P$. suaveolens e $D$. purpurea apresentaram rendimento acima de $60 \%$, enquanto $E$. uncinatum e sapucaia foram as que apresentaram menores rendimentos, $44,9 \%$ e $27,7 \%$ respectivamente.

Para A. lecointei o rendimento foi de $55,5 \%$, mas houve muitos toretes que não tiveram aproveitamento, devido grande incidência de alburno e também de brocas. A espécie sapucaia foi a que apresentou menor rendimento $(27,7 \%)$, influenciando diretamente o rendimento médio. 
Receitas e custos

Considerando os preços praticados pelos mercados formal e informal, com a volumetria de madeira serrada por espécie, foram obtidas as seguintes estimativas de receita, apresentadas na Tabela 7.

Tabela 7. Receitas estimadas considerando os preços de madeira serrada no mercado formal (REPMF) e informal (REPMI) de Santarém

\begin{tabular}{|c|c|c|}
\hline Nome científico & REPMF* (R\$) & REPMI** (R\$) \\
\hline H. heterocarpum (Angelim-pedra) & $6.691,88$ & $6.177,12$ \\
\hline V. assua (Cedrorana) & $5.108,11$ & $4.743,25$ \\
\hline P. suaveolens (Fava-timborana) & $2.281,16$ & $1.792,34$ \\
\hline A. leiocarpa (Garapeira) & $1.788,57$ & $1.589,84$ \\
\hline M. itauba (Itaúba) & $2.693,46$ & $1.958,88$ \\
\hline A. burchellii (Louro-rosa) & $4.865,25$ & $4.491,00$ \\
\hline M. huberi (Maçaranduba) & $18.905,04$ & $18.905,04$ \\
\hline A. lecointei (Muiracatiara) & $26.695,57$ & $19.414,96$ \\
\hline E. uncinatum (Quaruba) & $2.849,70$ & $2.239,05$ \\
\hline L. pisonis (Sapucaia) & 455,40 & 328,90 \\
\hline D. purpurea (Sucupira-amarela) & $1.329,21$ & $1.181,52$ \\
\hline Total & 73.663,35 & $62.821,90$ \\
\hline
\end{tabular}

*REPMF - receita estimada pelo preço de mercado formal

**REPMI - receita estimada pelo preço de mercado informal

A diferença entre as receitas foi de $\mathrm{R} \$ 10.841,45 \mathrm{e}$ somente a espécie maçaranduba obteve a mesma estimativa. As espécies Manilkara huberi e Astronium lecointei representaram mais de $60 \%$ das receitas estimadas.

Os custos obtidos pela cooperativa e os com previsão de encargos sociais e trabalhistas estão apresentados na Tabela 8. Os itens de custo avaliados foram: materiais, equipamento, combustível e mão-de-obra.

Tabela 8. Custos obtidos na atividade de extração e beneficiamento de resíduos florestais pós-colheita na Área de Manejo Floresta da COOMFLONA

\begin{tabular}{|c|c|c|}
\hline Descrição itens & $\mathrm{CSE}^{*}(\mathbf{R} \$)$ & $\mathbf{C C E}^{* *}(\mathbf{R} \$)$ \\
\hline \multicolumn{3}{|l|}{ Materiais } \\
\hline EPIs & $1.890,00$ & $1.890,00$ \\
\hline Fardamentos & 360,00 & 360,00 \\
\hline Alimentação & $6.468,00$ & $6.468,00$ \\
\hline Ferramentas de trabalho & $3.773,86$ & $3.773,86$ \\
\hline Medicamento/Kits primeiros socorros & 217,00 & 217,00 \\
\hline Sub-total & $12.708,86$ & $12.708,86$ \\
\hline \multicolumn{3}{|l|}{ Equipamentos } \\
\hline Aluguel de skidder & $9.360,00$ & $9.360,00$ \\
\hline Aluguel de carregadeira & $10.400,00$ & $10.400,00$ \\
\hline Depreciação motosserras & 435,20 & 435,20 \\
\hline Depreciação Serraria portátil & $1.557,41$ & $1.557,41$ \\
\hline Depreciação caminhão truck $3 / 4$ & $1.611,11$ & $1.611,11$ \\
\hline
\end{tabular}

\begin{tabular}{|c|c|c|c|}
\hline Depreciação Kombi & & $1.305,55$ & $1.305,55$ \\
\hline & Sub-total & $24.669,27$ & $24.669,27$ \\
\hline \multicolumn{4}{|l|}{ Combustível } \\
\hline Gasolina & & $3.493,70$ & $3.493,70$ \\
\hline Diesel & & $1.564,56$ & $1.564,56$ \\
\hline Óleo 2T & & 507,00 & 507,00 \\
\hline \multirow[t]{2}{*}{ Lubrificante } & & 644,00 & 644,00 \\
\hline & Sub-total & $6.209,26$ & $6.209,26$ \\
\hline \multicolumn{4}{|l|}{ Mão-de-obra } \\
\hline Operadores de motosserra & & $3.510,00$ & $9.852,48$ \\
\hline Ajudantes & & $11.432,50$ & $13.379,22$ \\
\hline Marreteiro & & 810,00 & $1.007,64$ \\
\hline \multirow[t]{2}{*}{ Operador serraria portátil } & & $4.430,00$ & $5.933,88$ \\
\hline & Sub-total & $20.182,50$ & $30.173,22$ \\
\hline Total & & $63.769,89$ & $73.760,61$ \\
\hline
\end{tabular}

*Custo sem encargos sociais e trabalhistas na mão-de-obra

**Custo com previsão de encargos sociais e trabalhistas na mãode-obra

As receitas também foram estimadas com a previsão de venda da madeira na forma de dormente, juntamente com a madeira serrada. No entanto, houve redução no volume total de madeira beneficiada em decorrência à estimativa de perda de $30 \%$ na geração dos dormentes a partir dos resíduos com comprimento $\geq 2,80 \mathrm{~cm}$. Os valores obtidos para o uso múltiplo dos resíduos estão apresentados na Tabela 9.

Tabela 9. Receitas estimadas com a venda de madeira na forma de dormente e madeira serrada provenientes do beneficiamento dos resíduos florestais pós-colheita na Área de Manejo Florestal da COOMFLONA

\begin{tabular}{|c|c|c|c|c|c|c|c|}
\hline Espécie & $\begin{array}{c}\mathbf{N} \\
\text { dormentes }\end{array}$ & $\begin{array}{c}\mathbf{V} \\
\text { madeira } \\
\text { serrada } \\
\left(\mathbf{m}^{3}\right)\end{array}$ & $\begin{array}{l}\text { Dormentes } \\
\text { (R\$) }\end{array}$ & $\begin{array}{c}\text { RMF } \\
\text { (R\$) }\end{array}$ & $\begin{array}{l}\text { RMI } \\
\text { (R\$) }\end{array}$ & $\begin{array}{c}\text { RMF+D } \\
(\mathbf{R})\end{array}$ & $\underset{(\mathbf{R} \$)}{\mathbf{R M I}+\mathbf{D}}$ \\
\hline H. heterocarpum & 42 & 2,7554 & $11.340,00$ & $1.791,01$ & $1.653,24$ & $13.131,01$ & $12.993,24$ \\
\hline V. assua & 0 & 7,2973 & 0,00 & $5.108,11$ & $4.743,24$ & $5.108,11$ & $4.743,24$ \\
\hline P. suaveolens & 0 & 3,2588 & 0,00 & $2.281,16$ & $2.281,16$ & $2.281,16$ & $1.792,34$ \\
\hline A. leiocarpa & 4 & 1,1876 & $1.080,00$ & $1.068,84$ & 950,08 & $2.148,84$ & $2.030,08$ \\
\hline M. itauba & 6 & 0,9635 & $1.620,00$ & $1.059,85$ & 770,80 & $2.679,85$ & $2.390,80$ \\
\hline A. burchellii & 0 & 7,4850 & 0,00 & $4.865,25$ & $4.491,00$ & $4.865,25$ & $4.491,00$ \\
\hline M. huberi & 72 & 6,1544 & $19.440,00$ & $5.538,96$ & $5.538,96$ & $24.978,96$ & $24.978,96$ \\
\hline A. lecointei & 0 & 24,2687 & 0,00 & $26.695,57$ & $19.414,96$ & $26.695,57$ & $19.414,96$ \\
\hline E. uncinatum & 0 & 4,0710 & 0,00 & $2.849,70$ & $2.239,05$ & $2.849,70$ & $2.239,05$ \\
\hline L. pisonis & 1 & 0,3918 & 270,00 & 352,62 & 254,67 & 622,62 & 524,67 \\
\hline D. purpúrea & 3 & 0,4487 & 810,00 & 403,83 & 358,96 & $1.213,83$ & $1.168,96$ \\
\hline
\end{tabular}

Total

\begin{tabular}{lllllll}
128 & 58,2822 & $34.560,00$ & $52.014,90$ & $42.696,12$ & $86.574,90$ & $76.767,30$ \\
\hline
\end{tabular} Onde: RMF - receita de madeira serrada pelo mercado formal; RMI - receita de madeira serrada pelo mercado informal; $R M F+D$ - receita de madeira serrada pelo mercado formal e de dormentes; e RMI+D - receita de madeira serrada pelo mercado informal e de dormentes. 
Avaliação dos cenários

Os resultados de custos e receitas dos cenários estudados estão apresentados na Tabela 10.

Tabela 10. Custos e receitas nos cenários avaliados

\begin{tabular}{cccc}
\hline Cenários & $\begin{array}{c}\text { Custo total } \\
(\mathbf{R} \$)\end{array}$ & $\begin{array}{c}\text { Receita bruta } \\
\text { estimada }(\mathbf{R} \mathbf{})\end{array}$ & $\begin{array}{c}\text { Receita líquida } \\
\text { estimada }(\mathbf{R} \mathbf{)}\end{array}$ \\
\hline 1 & $63.769,89$ & $73.663,35$ & $9.893,46$ \\
2 & $63.769,89$ & $62.821,90$ & $-947,99$ \\
3 & $73.760,61$ & $73.663,35$ & $-97,26$ \\
4 & $73.760,61$ & $62.821,90$ & $-10.938,71$ \\
5 & $63.769,89$ & $86.574,90$ & $22.805,01$ \\
6 & $63.769,89$ & $76.767,30$ & $12.997,41$ \\
7 & $73.760,61$ & $86.574,90$ & $12.814,29$ \\
8 & $73.760,61$ & $76.767,30$ & $3.006,69$ \\
\hline
\end{tabular}

O cenário 5 que corresponde aos custos pagos pela cooperativa e as receitas estimadas com a venda da madeira serrada pelo preço do mercado formal e destinação de parte da produção para dormentes, foi o que gerou melhor rentabilidade com $\mathrm{R} \$ 22.805,01$ de lucro estimado. Entretanto, o cenário 4 que corresponde aos custos com previsão de encargos sociais e trabalhistas que foi avaliado com a venda da madeira serrada no mercado informal, obteve o pior desempenho com prejuízo de $\mathrm{R} \$ 10,938,71$.

Os cenários 2, 3 e 4 apresentaram rentabilidade negativa, sendo todos com a estimativa somente da venda da madeira serrada. Nos cenários 2 e 4 , mesmo com o valor de custo pago pela COOMFLONA e estimada com os encargos sociais e trabalhistas, os lucros foram negativos quando comparado com a receita da madeira serrada pelo mercado informal.

No cenário 3, o lucro estimado ficou em R\$ -97,26 com os custos acrescidos dos encargos sociais e a madeira serrada vendida para o mercado formal, portanto mais próximo do ponto de equilíbrio em que os custos e receitas totais são iguais a zero.

\section{Discussão}

Tonini e Ferreira (2004), trabalhando com madeira em tora de Hymenolobium heterocarpum (angelim-pedra) obtiveram rendimento acima de $60 \%(66,2 \%)$. Para a espécie Mezilaurus itauba (itaúba), Biasi e Rocha (2007) obteve rendimento médio de madeira serrada de $54 \%$ e Garcia et al. (2012) teve 49,6\%, no entanto ambos foram para o beneficiamento de madeira em tora.

Para a espécie Astronium lecointei (muiracatiara), Marchesan (2012) obteve rendimento de 66\%, também trabalhando com madeira em tora. Já Souza (2006), avaliou o rendimento de madeira serrada da sapucaia por meio de uma serraria portátil e obteve $50,8 \%$ de aproveitamento, e afirmou que o diâmetro e a sanidade das toras foram os principais fatores que influenciaram no resultado.

Garcia (2011), estudou o aproveitamento dos resíduos de copa da espécie Manilkara huberi no município de Portel, Estado do Pará, e obteve um rendimento de $17 \%$. No entanto, estes resíduos foram beneficiados em uma serraria convencional, sendo um dos motivos, pelo baixo rendimento e foi recomendado investimento na adequação da indústria de transformação e equipamentos para ter eficácia no aproveitamento dos resíduos e assim oferecer qualidade aos produtos gerados.

É importante ressaltar a escassez de trabalhos envolvendo o beneficiamento de resíduos pós-colheita, mas os resultados obtidos neste estudo mostram a possibilidade de obter bons rendimentos, e em certos casos superiores as serrarias convencionais. Nas indústrias madeireiras, muitas técnicas estão sendo desenvolvidas e aplicadas, mas, mesmo assim, o rendimento da madeira serrada fica em torno de 50\% (Garcia et al. 2012).

Em relação aos custos, de maneira geral os equipamentos e mão-de-obra foram mais representativos ao valor do custo total. Sendo que nos custos sem os encargos sociais, os equipamentos foram o maior custo, com R\$ 24.669,27 (39\%). No entanto, quando foram previstos os encargos sociais, o item mão-de-obra foi superior com $\mathrm{R} \$ 30.173,22$ (41\%). A diferença entre os dois custos foi de $\mathrm{R} \$ 9.990,72$, representando um aumento de $15,67 \%$ em relação aos custos reais pagos pela COOMFLONA. Esta porcentagem a mais nos custos teria importância, pois garantiria todos os direitos trabalhistas e a participação no sistema previdenciário da equipe envolvida na atividade e desta forma agregaria o pagamento justo pela matéria-prima.

Considerando os valores de custo pagos pela cooperativa e o volume beneficiado, o custo produzido foi de $\mathrm{R} \$ 758,26 \mathrm{~m}^{-3}$, ou seja, este é o valor mínimo para madeira serrada ser vendida, independente da espécie. A média de preços praticados no mercado formal e informal foram $\mathrm{R} \$ 836,36$ e $\mathrm{R} \$ 700,00$, respectivamente. Por conseguinte, a madeira serrada dos resíduos da COOMFLONA custa em média mais $\mathrm{R} \$ 58,26$ comparativamente ao preço médio no mercado informal e custa menos $\mathrm{R} \$ 78,10$ do que o preço médio no mercado formal.

Com a previsão dos encargos sociais no custo da mãode-obra, o preço mínimo por metro cubico de madeira serrada dos resíduos seria de $\mathrm{R} \$ 877,05$. Valor que estaria $\mathrm{R} \$ 40,69$ acima do preço médio do mercado formal e $\mathrm{R} \$$ 118,79 acima do valor estipulado com os custos pagos pela cooperativa.

Os resultados apresentados mostram agregação de valor significativo com a inclusão da venda da madeira na forma de dormentes. Os valores tiveram uma valorização de $17,53 \%$ e $22,20 \%$ em relação às receitas estimadas somente com a venda da madeira serrada.

$\mathrm{O}$ volume aproveitado estimando o uso de dormente foi de $14,6227 \mathrm{~m}^{3}$ e $72,9049 \mathrm{~m}^{3}$ quando somado com o volume de madeira serrada. Em relação às espécies destinadas para dormentes, somente Mezilaurus itauba apresentou leve desvalorização com o uso múltiplo. A receita líquida estimada com a venda de madeira serrada no mercado formal e dormentes foi de $\mathrm{R} \$ 2.679,85$, enquanto que para a venda somente de madeira serrada para o mesmo mercado a receita líquida estimada ficou em $\mathrm{R} \$ 2.693,96$.

De maneira geral, as receitas estimadas foram positivas, caso seja colocada parte da produção para o mercado de dormentes. Os indicaram que o uso múltiplo pode agregar mais valor ao produto advindo dos resíduos florestais pós-colheita. Todavia, o cenário 7 foi o que apresentou a melhor forma de remuneração ao produto, pois os custos envolveram todos os direitos trabalhistas aos manejadores e a receita estimada agregou o máximo de valor a madeira beneficiada dos resíduos florestais.

Deve se ressaltar que o objetivo principal foi a madeira beneficiada dos galhos e que os subprodutos ainda gerados 
com o desdobro não tiveram destinação específica, mas poderia ser agregado valor na possível produção de carvão e lenha, como matéria prima utilizada na secagem de madeira em estufas, ou até mesmo na cogeração de energia elétrica.

\section{Conclusões}

A atividade de extração e beneficiamentos dos resíduos florestais pós-colheita é rentável, podendo gerar mais recursos na possibilidade do uso múltiplo desta matéria prima.

O aproveitamento dos resíduos florestais agrega valor ao recurso florestal, garantindo sua conservação como fonte de renda e geração de emprego.

A colheita e processamento de resíduos florestais póscolheita propicia benefícios socioeconômicos a comunidades tradicionais organizados em arranjos produtivos residentes em Unidades de Conservação de Uso Sustentável.

\section{Agradecimentos}

Agradecemos a Cooperativa Mista da Flona do Tapajós (COOMFLONA) pela oportunidade e investimento na pesquisa.

Ao ICMBio pelo incentivo e apoio a pesquisa dentro da Unidade de Conservação.

E ao Conselho Nacional de Desenvolvimento Científico e Tecnológico (CNPq) pela oportunidade de bolsa ao primeiro autor durante o mestrado.

\section{Referências}

Andrade DF, Gama JRV, Melo LO, Ruschel AR (2015) Inventário florestal de grandes áreas na Floresta Nacional do Tapajós, Pará, Amazônia, Brasil. Biota Amazônia, 5(1): 109-115. doi: http://dx.doi.org/10.18561/21795746/biotaamazonia.v5n1p109-115

Azevedo TL, Mello AA, Ferreira RA, Sanquetta CR, Nakajima NY (2011) Equações hipsométricas e volumétricas para um povoamento de Eucalyptus sp. localizado na FLONA do Ibura, Sergipe. Revista Brasileira de Ciências Agrárias, 6(1): 105-112. doi:10.5039/agraria.v6i1a861

Barreto WF, Leão FM, Menezes MC, Souza DV (2014) Equação de volume para apoio ao manejo comunitário de empreendimento florestal em Anapú, Pará. Pesquisa Florestal Brasileira, 34(80): 1-9. doi: 10.4336/2014.pfb.34.80.721

Barros PLC, Silva-Júnior AT (2009) Equação de volume para árvores de uma floresta tropical densa no município de Anapú, oeste do estado do Pará, Amazônia oriental. Revista de Ciências Agrárias, 51: 115-126.

Batista JLF, Marquesini M, Viana VM (2004) Equações de volume para árvores de caxeta (Tabebuia cassinoides) no Estado de São Paulo e sul do Estado do Rio de Janeiro. Scientia Forestalis, 65: 162-175.

BRASIL (2000). Decreto-lei $n^{o} 9.985$, de 18 de julho de 2000. Regulamenta o art. 225, $\$ 1^{\circ}$, incisos I, II, III e VII da Constituição Federal, institui o Sistema Nacional de Unidades de Conservação da Natureza. Diário Oficial da República Federativa do Brasil, Ministério do Meio Ambiente. Brasília, DF, 18 jul. 2000. Seção 1, p. 1.

BRASIL (2009) Resolução Conama $n^{\circ} 406$, de 2 de fevereiro de 2009. Estabelece parâmetros técnicos a serem adotados na elaboração, apresentação, avaliação técnica e execução de Plano de Manejo Florestal SustentávelPMFS com fins madeireiros, para florestas nativas e suas formas de sucessão no bioma Amazônia. Ministério de Meio Ambiente, Brasília, DF, 4 p.

Cabacinha CD, Scolforo JRS, Thiersch CR, Sales NLP, Carvalho LR (2013) Uma nova abordagem para o método geométrico usando o índice da parábola. Ciência Florestal, 23(1): 261-271.

Campos JCC, Leite HG (2009) Mensuração florestal: perguntas e respostas. $3^{\text {th }}$ Edition. Viçosa: Editora UFV. 542 p.

Couto HTZ, Bastos NLM (1987) Modelos de equações de volume e relação hipsométricas para plantações de Eucalyptus no Estado de São Paulo. IPEF, 37: 33-44.

Cysneiros VC, Pelissari AL, Machado SA, Figueiredo Filho A, Souza L (2017) Modelos genéricos e específicos para estimativa do volume comercial em uma floresta sob concessão na Amazônia. Scientia Forestalis, 45(114): 295-304. doi: dx.doi.org/10.18671/scifor.v45n114.06

Estatcamp - Consultoria em estatística e qualidade (2014) Action Stat. Version 3.6.331.450 build 7 São Carlos, São Paulo, Brasil.

Ferreira MZ (2009) Modelagem da influência de variáveis ambientais no crescimento e na produção de Eucalyptus $s p$. Thesis. Universidade Federal de Lavras, Lavras. 112p.

Gomes KMA, Silva Ribeiro RB, Gama JRV, Andrade DFC (2018) Eficiência na estimativa volumétrica de madeira na Floresta Nacional do Tapajós. Nativa, 6(2): 170-176. doi:http://dx.doi.org/10.31413/nativa.v6i2.5237

Guimarães DP, Leite HG (1996) Influência do número de árvores na determinação de equação volumétrica para Eucalyptus grandis. Scientia Forestalis, 50: 37-42.

IBGE - Instituto Brasileiro de Geografia e Estatística (2012) Manual técnico da vegetação brasileira. $2^{\text {nd }}$ Edition Revisada e ampliada, Brasília. 271p.

IBAMA - Instituto Brasileiro do Meio Ambiente e dos Recursos Naturais Renováveis (2004) Floresta Nacional do Tapajós - Plano de Manejo. Brasília, 580p.

Leite FSL (2009) Estimativa do volume de madeira a partir do diâmetro da cepa em uma área explorada de floresta amazônica de terra firme. Dissertation, Universidade de Brasília, Brasília.74p.

Miranda LC, Paro BAV, Costa GR (2014) Estimativa do volume em árvores de Hymenaea coubaril L. e Trattinnickia burserifolia Mart. no norte de Mato Grosso. Nativa, 2(4): 219-223. doi:10.14583/23187670.v02n04a06

Moura JB (1994) Estudo da forma do fuste e comparação de métodos de estimativa volumétrica de espécies florestais da Amazônia brasileira. Dissertation, Universidade Federal do Paraná, Curitiba. 114p.

Oliveira RCA, Rode R, Gama JRV, Almeida EC (2017) Equações volumétricas para Couratari stellata A.C Smith (Tauarí) na Floresta Nacional do Tapajós. Nativa, 5(2): 138-144. doi: 10.5935/2318-7670.v05n02a10

Pinho GSC, Fiedler NC, Guimarães PP, Silva GF, Santos J (2009) Análise de custos e rendimentos de diferentes métodos de corte de cipós para produção de madeira na 
floresta nacional do Tapajós. Acta Amazonica, 39(3): 555-

560.

Rolim SG, Couto HTZ, Jesus RM, França JT (2006) Modelos volumétricos para a Floresta Nacional do Tapirapé-Aquirí, Serra dos Carajás (PA). Acta Amazonica, 36(1): 107-114.

Scolforo JRS (2005) Biometria florestal: parte I: modelos de regressão linear e não linear: parte II: modelos para relação hipsométricas, volume, afilamento e peso da matéria seca. Lavras: UFLA/FAEPE. 352 p.

SEMAS - Secretaria Estadual do Meio Ambiente e Sustentabilidade (2015) Instrução normativa $n^{o} 5$ de 10/09/2015. Dispõe sobre procedimentos técnicos para elaboração, apresentação, execução e avaliação técnica de Plano de Manejo Florestal Sustentável - PMFS nas florestas nativas exploradas ou não e suas formas de sucessão no Estado do Pará, e dá outras providências. Belém.

Silva JNM, Carvalho JOP, Lopes JCA, Carvalho MSP (1984) Equações de volume para a floresta nacional do Tapajós. Boletim de Pesquisa Florestal, Colombo, 8: 5063.

Silva-Ribeiro RB, Gama JRV, Melo LO (2014) Seccionamento para cubagem e escolha de equações de volume para a Floresta Nacional do Tapajós. Cerne, 20(4): 605-612. doi:10.1590/01047760201420041400

Soares CPB, Neto FP, Souza AL (2011a) Dendrometria e inventário florestal. Viçosa. Ed. UFV; 272p.

Soares CPB, Martins FB, Leite Junior HU, Silva GF, Figueiredo LTM (2011b) Equações hipsométricas, volumétricas e de Taper para onze espécies nativas. Revista Árvore, Viçosa, MG, 35(5): 1039 - 1051.

Taffarel M, Carvalho JOP, Melo LO, Silva MG, Gomes JM, Ferreira JER (2014) Efeito da silvicultura pós colheita na população de Lecythis lurida (Miers) Mori em uma floresta de terra firme na Amazônia brasileira. Ciência Florestal, 24(4):887-896.

Thaines F, Braz EM, Mattos PP, Thaines AAR (2010) Equações para estimativa de volume de madeira para a região da bacia do Rio Ituxi, Lábrea, AM. Pesquisa Florestal Brasileira, 30(64): 283-289, 2010. doi: 10.4336/2010.pfb.30.64.283

Thomas C, Andrade CM, Scheneider PR, Finger CAG (2006) Comparação de equações volumétricas ajustadas com dados de cubagem e análise de tronco. Ciência Florestal, 16(3): 319-327.

Tonini H, Borges RA (2015) Equação de volume para espécies comerciais em Floresta Ombrófila Densa no Sul de Roraima. Pesquisa Florestal Brasileira, 35(82): 111117. doi: 10.4336/2015.pfb.35.82.738

Trevisor TT (2011) Anatomia comparada do lenho de 64 espécies arbóreas de ocorrência natural na floresta tropical amazônica no estado do Pará. Dissertation, Universidade de São Paulo, Piracicaba. 217p.

Valente MDR, Queiroz WT, Pinheiro JG, Monteiro LAS (2011) Modelo de predição para o volume total de Quaruba (Vochysia imundata Ducke) via análise de fatores e regressão. Revista Árvore, 35(2): 307-317. 